\title{
Biomass-cover relationship for eelgrass meadows
}

4

5 Jacob Carstensen $^{1 *}$, Dorte Krause-Jensen ${ }^{2}$, Thorsten J. S. Balsby ${ }^{2}$

6

$7 \quad{ }^{1}$ Department of Bioscience, Aarhus University, Frederiksborgvej 399, DK-4000

8 Roskilde, Denmark

$9 \quad{ }^{2}$ Department of Bioscience, Aarhus University, Vejlsøvej 25, DK-8600 Silkeborg,

10 Denmark

11 * corresponding author: jac@dmu.dk; Phone: +45 87158596; Fax: +45 87155010

12

13 Keywords: Eutrophication; light attenuation; monitoring; Secchi depth; shallow coastal ecosystems;

14 Zostera marina

15

16 


\section{Abstract}

19 Eelgrass meadows play key roles in coastal ecosystems and the extent of the standing biomass is focal to address ecosystem functioning. Eelgrass cover is commonly assessed in marine monitoring programs while biomass sampling is destructive and expensive. Therefore, we have proposed a functional relationship that translates eelgrass cover into aboveground biomass using site-specific information on Secchi depth or light attenuation. The relationship was estimated by non-linear regression on 791 combined observations of eelgrass cover and biomass from eight different coastal sites in Denmark. Eelgrass biomass initially increased with cover and flattened out as cover exceeded 40-50\% due to increased self-shading. Decreasing light energy with depth reduced the eelgrass biomass potential (assessed at 100\% cover), and this reduction was stronger for coastal sites with lower water transparency. Moreover, the biomass potential varied seasonally from around $110-140 \mathrm{~g} \mathrm{DW} \mathrm{m}^{-2}$ in spring months to a peak of $241 \mathrm{~g} \mathrm{DW} \mathrm{m}^{-2}$ in August, consistent with other seasonal studies. The model explained $56 \%$ of the variation in log-transformed biomasses, but significant variation between coastal sites still remained, deviating between $-23 \%$ and $39 \%$ from the mean relationship. These site-specific deviations could be due to differences in losses related to grazing, drifting algae and epiphytes, better light capture by dense canopies, as well as differences in how well light conditions within eelgrass meadows are represented by actual measurements of Secchi depth and light attenuation. The relationship can be employed to estimate eelgrass biomass of entire coastal ecosystems from observations of eelgrass cover and depth. 
INTRODUCTION

Eelgrass meadows play key functional roles in coastal ecosystems because eelgrass is an engineering species capable of modifying the benthic habitat structurally and metabolically (Gutierrez et al. 2011; Hemminga and Duarte 2000). The meadows increase the structural complexity of the seafloor and provide habitat for a variety of species, thereby stimulating biodiversity (Plummer et al. 2013). They are also highly productive and hence support secondary production and have a major effect on nutrient and carbon cycling in the coastal zone. In some areas eelgrass constitutes an important food source for birds (Clausen et al. 2012), but overall few species graze directly on eelgrass, and most of the biomass enters the detrivore food web or is buried (Cebrián et al. 1997). Moreover, eelgrass meadows dissipate wave energy and stabilize the sediments within and surrounding the meadows, which help protect the coast from erosion. The reduced wave energy further promotes particles trapping, and thereby contributes to increased water clarity as well as carbon sequestration in eelgrass sediments (van der Heide et al. 2011; McGlathery et al. 2012; Duarte et al. 2013). Seagrass sediments have indeed been identified as globally important carbon stocks (Fourqurean et al. 2012). These eelgrass-mediated ecosystem services depend on the standing biomass and the area cover of the meadows, which are, therefore, key variables to address in monitoring and management of coastal ecosystems.

Mosaics of eelgrass patches and meadows occur on soft/sandy bottom of relatively protected waters from the shore and as deep as light levels allow, with the meadows confined to shallow depth ranges in turbid waters and extending deeper in clear waters (Duarte et al. 2007). The abundance of eelgrass typically declines exponentially with depth paralleling the extinction of light (Duarte 1991; Krause-Jensen et al. 2000).

Physical exposure may reduce the abundance in shallow water, resulting in a bell-shaped distribution with depth (Krause-Jensen et al. 2003), and poor sediment quality or reduced oxygen levels may also lead to reduced eelgrass abundance (Koch 2001; Krause-Jensen et al. 2011). As the meadows respond to changing water and sediment quality, their distribution and abundance are often used as indicators of ecological status (Marbà et al. 2013). 
Biomass expressed as dry weight of carbon per $\mathrm{m}^{2}$ seafloor is a relevant unit for quantifying eelgrass abundance and estimating structural and functional roles of the plant. Carbon biomass can also be quantified for other ecosystem components, which potentially allows addressing carbon flow through the ecosystem via coupling to process rates. But direct determination of biomass is destructive and resource-demanding as it requires harvesting the plants by divers and many biomass samples would be required to determine the largescale eelgrass abundance. Eelgrass cover, assessed by divers, underwater video or remote sensing, is an alternative, non-destructive variable that is less costly compared to measuring biomass and suitable for assessment of eelgrass distribution and abundance at larger spatial scale. However, assessments of eelgrass cover do not couple as directly to ecosystem functions as biomass observations do. The combined benefit of non-destructive, large-scale and low-cost cover assessments and detailed biomass information relating more directly to ecological functions, could be obtained if robust relationships between coverage observations and biomass could be established to predict biomass distribution from coverage. For instance, observations of eelgrass cover along depth gradients from the shore and to the deepest extension of the meadows could be converted to biomass on the basis of such biomass-cover relationships. This would allow scaling cover to biomass over larger areas and potentially assessing eelgrass functions at an ecosystem scale.

Here we establish and test a generic relationship between eelgrass biomass and cover, taking into account factors such as depth, water clarity and time of the year. The relationship is developed based on monitoring data from the Danish coastal waters with combined information on eelgrass cover and biomass along depth gradients. The relationship allows the conversion of estimates of eelgrass cover to biomass along depth gradients. We thereby provide the basis for obtaining estimates of eelgrass biomass based on large-scale and long-term data sets on eelgrass cover. This opportunity is of great value e.g. in Denmark where the majority of monitoring data on eelgrass distribution and abundance is available solely as cover estimates. 
MATERIALS AND METHODS

Eelgrass cover has been monitored routinely since 1989 in 50 different estuaries and coastal embayments (referred to as coastal sites in the following) within the Danish National Aquatic Monitoring and Assessment Program (DNAMAP). In addition to the regular eelgrass monitoring, data on the aboveground biomass of eelgrass were available from specific surveys in eight coastal sites which form the study areas of the current study (Table 1; Fig. S1). These data were extracted from the national marine monitoring database or from reports, in cases when data had not been submitted to the database. Eelgrass biomass was sampled between 1990 and 2009.

Eelgrass biomass and cover were sampled in the growth season (March to October) by regional monitoring authorities with support from consultants. Sampling was carried out according to the same general protocol by experienced divers that regularly participate in intercalibration exercises as part of the monitoring program. Biomass samples were obtained by harvesting the aboveground biomass within a frame placed randomly within the eelgrass meadows where these covered the seafloor. The frame size varied between coastal sites from 0.09 to $0.25 \mathrm{~m}^{2}$ and the number of samples per depth transect ranged between 1 and 24 . The samples were dried at $105^{\circ} \mathrm{C}$ (in few cases at $85^{\circ} \mathrm{C}$ ) for $24 \mathrm{~h}$ to constant weight and the biomass reported in g dry weight (DW) $\mathrm{m}^{-2}$. Before harvesting the biomass, the diver estimated the eelgrass cover within the frame in percent of the soft/sandy seafloor and recorded sampling depth. We quality-controlled the data by contacting the regional monitoring team and consulting monitoring reports to check that biomass estimates were correctly adjusted to varying frame sizes and represented aboveground biomass per $\mathrm{m}^{2}$. Data not conforming to the quality check were discarded. The resulting data set consisted of 852 combined biomass-cover observations distributed across eight coastal sites over the period 1990-2009 (Table 1).

The depth distribution of eelgrass biomass depends on the prevalent light conditions, and therefore seasonal means (March to September) of Secchi depth $\left(Z_{S D}\right)$ for the different coastal sites and years with eelgrass data 
were calculated. Secchi depths were measured in all eight coastal sites as part of the DNAMAP; although not within the eelgrass meadows but at stations in the deeper part of the coastal site. In these shallow coastal sites the Secchi disk was occasionally visible at the bottom (censored data) and therefore censored data regression was employed (Carstensen 2010). Secchi depth means (March-September) were estimated for each year in all coastal sites and combined with the eelgrass biomass data, except for Kertinge Nor and Helnæs Bugt where Secchi depth observations were too few in the year (1996) with eelgrass biomass data and a Secchi depth mean over multiple surrounding years was calculated instead. Additionally, the light attenuation coefficient $\left(K_{d}\right)$ has been estimated from underwater PAR (photosynthetically active radiation) profiles as part of DNAMAP in more recent years (Pedersen et al. 2014), which only partially overlap the biomass samples in time as opposed to Secchi depth, which has been monitored regularly as part of DNAMAP. Mean values of the product between $K_{d}$ and $Z_{S D}$ for the eight different sites were calculated for comparison with the biomass model described below.

\section{Eelgrass biomass model} mainly depends on the light energy reaching the eelgrass (Sand-Jensen and Borum 1991; Krause-Jensen et al. 2000), and this is a function of the depth of the sample $(Z)$ as well as the attenuation of light in the water column, expressed by the light attenuation coefficient $\left(K_{d}\right)$ which can be approximated from the Secchi depth eelgrass biomass and eelgrass cover, depth, and Secchi depth is derived step-by-step in the following. 
140 We assumed that eelgrass biomass is related to eelgrass cover through a saturation-type of response,

141 displaying almost proportionality at low eelgrass coverage (no competition for light) but levelling off at

142 increasing cover due to increased competition for light. This can be formulated as:

$143 \quad B(C, Z)=B_{\max }(Z) \cdot\left(1-\exp \left(-\frac{C(Z)}{k_{C}}\right)\right)$

144 where $B_{\max }(Z)$ is the maximum attainable biomass at a given depth, and $k_{c}$ is a parameter describing how fast

145 the relationship between biomass and cover levels off. Eelgrass biomass will approach $B_{\max }(Z)$ as $C(Z)$

146 increases towards $100 \%$.

147

148 The maximum biomass as a function of depth, $B_{\max }(Z)$, depends on the light-regulated reduction of biomass

149 with depth, assuming that a certain light level can sustain a certain biomass (steady-state assumption). The

150 effect of light-limited growth can be modeled using a simple hyperbolic tangent function (Platt and Jassby

151 1976)

152

$B_{\max }(Z)=B_{\max } \cdot \tanh \left(\frac{I(Z)}{I_{\text {sat }}}\right)$

153 where $B_{\max }$ is the maximum attainable biomass when there is no light limitation, $I(Z)$ is the irradiance at

154 depth $Z$, and $I_{s a t}$ is a parameter equal to the irradiance level yielding $76 \%$ of $B_{\max }$ (i.e. $\left.\tanh (1)=0.76\right)$. Using

155 Lambert-Beer's law with $K_{d}$ describing the light attenuation with depth the expression becomes

156

$B_{\max }(Z)=B_{\text {max }} \cdot \tanh \left(\frac{I_{0}}{I_{\text {sat }}} \cdot \exp \left(-K_{d} \cdot Z\right)\right)$

157

158 Assuming that the Secchi depth $\left(Z_{S D}\right)$ represents $20 \%$ (see discussion) of the surface irradiance (i.e.

$\left.159 K_{d}=\frac{-\log (0.2)}{z_{S D}}\right)$ the maximum eelgrass biomass becomes a function of $Z_{S D}$

160

$B_{\text {max }}(Z)=B_{\text {max }} \cdot \tanh \left(\frac{I_{0}}{I_{\text {sat }}} \cdot \exp \left(\log (0.2) \cdot \frac{Z}{Z_{S D}}\right)\right)$

162 Thus, combining Equations (1) and (4) the eelgrass biomass can be formulated as function of coverage,

163 Secchi depth and depth as: 
Measurements of eelgrass biomass typically have a right-skewed distribution with variation between replicate samples increasing with the mean. For analyzing measured biomasses it is therefore more relevant to consider the log-transform of the biomass

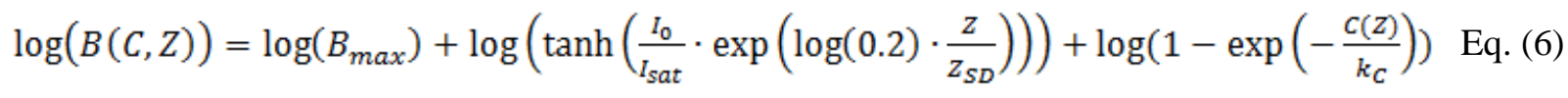

Eelgrass biomass accumulates during months when production exceeds respiration, which results in a seasonal effect on biomass in addition to the direct effect of light attenuation in the water column. This seasonal variation describing the balance between growth and respiration was modeled by estimating the parameter $B_{\max }$ specific to each month with biomass observations.

This non-linear model was fitted using the combined data set of eelgrass biomass, cover and Secchi depth by means of non-linear maximum likelihood regression (PROC MODEL in SAS 9.3; SAS Institute, Cary, NC). Model parameters were $k_{c}$ and $I_{0} / I_{\text {sat }}$ (describing the relative amount of surface radiation where light reduces growth by $24 \%$ ) as well as eight month-specific parameters for $B_{\max }$. The non-linear estimation routine iteratively found the optimal parameter estimates by ordinary least squares estimation. The eelgrass model was tested by examining the distribution of the residuals, plotting them versus depth and cover and analyzing their differences among coastal sites. The nature of the depth and cover relationships was assessed by plotting the marginal relationships of eelgrass biomass versus the two predictors (cover and depth), i.e. calculating eelgrass biomass adjusted for the predicted effect of cover and depth as well as interannual variations in Secchi depth. Finally, the applicability of the model was tested by applying the estimated relationship to four different transects, where cover and depth had been recorded. 


\section{RESULTS}

191

192

The combined data set (791 observations) represented a broad span of depths (0.7-7.8 m), Secchi depths (2.2-8.7 m), eelgrass cover (1-100\%), and eelgrass biomass (0.2-573 $\mathrm{g} \mathrm{DW} \mathrm{m}^{-2}$ ) (Table 1). Although there were differences in sampling efforts across the 8 coastal sites, the data set appeared reasonably balanced and not biased towards a single coastal site. All of the eight different months (March-October) used to describe the seasonal variation in $B_{\max }$ were sampled at least at two coastal sites.

Eelgrass biomass varied over three orders of magnitude with an overall tendency to decline at depths $>2 \mathrm{~m}$ (Fig. 1a). For observations representing full (100\%) eelgrass cover, the biomass varied from 26 to $546 \mathrm{~g} \mathrm{DW}$ $\mathrm{m}^{-2}$, while the highest biomass observation was actually measured for a cover of $85 \%$. Eelgrass cover spanned broadly across the entire depth range (Fig. 1b), which allowed for estimating the eelgrass biomass dependency on depth and cover with small risk of correlated parameter estimates, particularly $k_{c}$ and $I_{d} / I_{\text {sat. }}$. Eelgrass biomass increased with cover across different depth strata in a similar manner, showing an initial increase in biomass at low eelgrass cover before flattening when the cover exceeded 40-50\% (Fig. 2). Examining the data and the residuals generated from Eq. (6), two observations were identified as outliers (Fig. 2); both having eelgrass biomass above $100 \mathrm{~g} \mathrm{DW} \mathrm{m}^{-2}$ at a low cover of $1 \%$ and $10 \%$. These observations were subsequently excluded from the model estimation.

The eelgrass biomass modelled from Eq. 6 explained $56 \%\left(\mathrm{R}^{2}=0.56\right)$ of the total variation in the logtransformed biomass observations without any systematic departures over the prediction range (Fig. 3). The residual variation was considerable (Root MSE $=0.6469$ on the log-scale), corresponding to about $\pm 90 \%$ variation on individual observations. All parameter estimates were strongly significant (Table 2) and importantly, the correlation between the parameter estimates of $k_{c}$ and $I_{0} / I_{\text {sat }}$ was small $(\mathrm{r}=0.1243)$. This implied that the depth and cover terms of Eq. (6) were determined almost independently of each other. The parameter estimate of $k_{c}$ described that the eelgrass biomass reached a "saturation point" for eelgrass cover around 54\%. Similarly, the parameter estimate of $I_{\delta} / I_{\text {sat }}$ suggested that light limitation became important at 
depths where the surface irradiance was reduced to less than $30 \%$. The monthly parameter estimates for $B_{\max }$ 215 displayed a significant (Wald test statistic $=57.75 ; p<0.0001)$ and expected seasonal pattern increasing from around 110-140 $\mathrm{g} \mathrm{DW} \mathrm{m}^{-2}$ in the spring months to a peak of $241 \mathrm{~g} \mathrm{DW} \mathrm{m}^{-2}$ in August and then declined gradually in September and October to a level similar to that of June and July ( $170 \mathrm{~g} \mathrm{DW} \mathrm{m}{ }^{-2}$; Fig. 4).

The residuals of biomass estimates from Eq. (6) followed the normal distribution closely and did not show any systematic departures over the ranges of depth and cover (data not shown). However, the residuals varied significantly among coastal sites $\left(F_{8,781}=14.15 ; p=<0.0001\right)$. Accounting for site-specific differences only reduced the remaining residual variation slightly (Root MSE $=0.6038$ on the log-scale), corresponding to $\pm 83 \%$ variation on individual observations. Thus, eelgrass biomass observations were quite variable with a considerable amount of variation unaccounted for. Mean differences among coastal sites were between -0.26 and 0.33 on the log-scale (Table 3), corresponding to $-23 \%$ and $39 \%$ deviation from the biomass-cover relationship estimated over the entire data set. So in addition to the estimated relationship representing the average across all coastal sites, there were site-specific characteristics yielding overall higher or lower eelgrass biomass.

The marginal relationships between eelgrass biomass and depth (accounting for variations in cover, Secchi depth, and month of sampling through the model) showed different decreases with depth among the coastal sites, i.e. different "biomass attenuation" with depth (Fig. 5), which were caused by differences in light attenuation among sites. In Køge Bugt and The Sound that had the highest water transparency (Table 1), eelgrass biomass only decreased slightly between 0.7 and $7.8 \mathrm{~m}$ depth. Roskilde Fjord and Odense Fjord had less clear waters and eelgrass biomass decreased already at depths $>2 \mathrm{~m}$ (Fig. 5), although for Odense Fjord this was only clear from the estimated relationship as eelgrass biomass was not sampled deeper than $3.2 \mathrm{~m}$. Differences between the estimated marginal relationships and observations, adjusted for variations in eelgrass cover, interannual variation in Secchi depth and month of sampling, were large for Køge Bugt (residuals 35\% above the average) and The Sound (residual 21\% below the average) (Fig. 5, Table 3). This site-specific bias was smaller for Roskilde Fjord (-2\%) and Odense Fjord (-11\%). 
239 Similarly, the marginal relationships showed a steep proportional increase in eelgrass biomass with eelgrass 240 cover in the range $0-20 \%$, followed by a more gradual increase that almost flattened out when eelgrass cover 241 exceeded 40-50\% (Fig. 6). The relationships for the different sites were quite similar, since site-specific 242 differences were based on the ratio between eelgrass sampling depth and Secchi depth $\left(\frac{z}{z_{S D}}\right.$ in Eq. 6), that 243 exhibited small variations among sites (Table 1). As above, the relationship for Køge Bugt underestimated 244 eelgrass biomass observations, whereas the relationships for Roskilde Fjord, Odense Fjord and The Sound 245 overestimated biomass observations (cf. Table 3).

246 We calculated eelgrass biomass along four different transects where depth and eelgrass cover was monitored 247 as part of the national monitoring program (Fig. 7). All transects started at shallow depths and extended 248 beyond the eelgrass depth limits; however, depth did not increase continuously due to bottom topography. 249 Eelgrass biomass largely followed variations in eelgrass cover, displaying shifts between dense meadows 250 and bare sediments, but with relatively smaller biomass at deeper depths, which was most clearly seen in 251 Køge Bugt and Roskilde Fjord (Fig. 7a,c). Eelgrass biomass was predicted at 100-200 g DW m ${ }^{-2}$ in the dense 252 meadows, whereas the less dense patches had lower biomass. 


\section{DISCUSSION}

We developed a general model that describes eelgrass biomass based on information on eelgrass cover for a given depth and season and with associated information on water transparency of the coastal site. Hence, the model allows a general conversion of eelgrass cover data to biomass. This model may constitute a useful tool as information on eelgrass biomass is highly valuable for addressing functional aspects of eelgrass meadows but sampling of biomass is destructive and costly while eelgrass cover is much easier and less costly to assess on the large scale. As eelgrass biomass and cover at given depths are highly dependent on light attenuation, the inclusion of a light attenuation term in the model enables a realistic fit to local light conditions and makes the model generally applicable for areas showing seasonality of eelgrass biomass similar to that of mid-latitude Danish coastal waters. The model also allows for converting aerial surveys of eelgrass cover into biomass, provided that the bathymetry and Secchi depth of the area are known.

\section{Light regulation of eelgrass biomass}

The model provided estimates of the light level $\left(\mathrm{I}_{0} / I_{\text {sat }}\right)$ needed to support maximum eelgrass biomass, based on the assumption that Secchi depths represent $20 \%$ of the surface irradiance (PAR). This assumption corresponds to $K_{d} \cdot Z_{S D}=-\log (0.2)=1.61$. Although this value corresponds to values reported for open seawater $(\sim 1.5-1.7), K_{d} * z_{S D}$ is generally higher in estuaries and coastal waters ( 1.9-3.9) influenced by dissolved organic matter from land (Koenings and Edmundson 1991). The more recent monitoring observations of the light attenuation coefficient suggest that $K_{d} \cdot z_{S D}$ ranges from 1.7 in Odense Fjord and South Funen Archipelago to 2.1 in Roskilde Fjord (data not shown), corresponding to $12-18 \%$ of surface irradiance at the Secchi depth. These values are higher than the value employed in the eelgrass biomass model, but $K_{d}$ and $Z_{S D}$ are measured at deeper monitoring stations centrally located in the study sites, whereas eelgrass biomass was sampled in shallower nearshore environments, where sediment resuspension is more pronounced. Increased scattering from resuspended particles in the shallow environments reduces $K_{d} \cdot z_{S D}$ (Gallegos et al. 2011), justifying the lower value applied in the model. Furthermore, eelgrass 
biomass was sampled over a period (1990-2009) when nutrient inputs from Denmark were significantly

281 reduced (Carstensen et al. 2006), which also led to a decrease in the ratio between scattering and absorbance

(Pedersen et al. 2014). This suggests that $K_{d}{ }^{*} z_{S D}$ has increased over time and therefore was lower during the period of eelgrass biomass sampling, consistent with Pedersen et al. (2014) reporting an increase in $K_{d}{ }^{*} Z_{S D}$ in Roskilde Fjord from 1.8 (1985) to 2.2 (2008-2009). Unfortunately, light measurements within the eelgrass meadows were not available, but $K_{d} \cdot z_{S D}=1.61$ is not unrealistic given the arguments raised above.

\section{The effect of light attenuation on eelgrass biomass was described as a biomass attenuation (Duarte 1991)} with depth, and Eq. (2) and the $\mathrm{I}_{0} / I_{\text {sat }}$-value (Table 2) suggest that $73 \%$ of $B_{\max }$ can be obtained at $30 \%$ of the surface irradiation, $55 \%$ of $B_{\max }$ can be obtained at $20 \%$ surface irradiation, and $30 \%$ of $B_{\max }$ can be obtained at $10 \%$ surface irradiation. The nature of the light-dependency for eelgrass biomass is poorly documented in the literature but our $\mathrm{I}_{0} / I_{\text {sat }}$-value is possibly larger than the light level needed to support the depth limit of eelgrass, for which there is considerable documentation. Based on laboratory studies Olesen (1996) found that $11 \%$ of surface irradiance was needed to support eelgrass growth on an annual basis. Field studies have reported somewhat higher light levels at the depth limit probably because loss of biomass due to other factors than respiration contributes to defining the depth limit. Assuming $10 \%$ of the surface light at the Secchi depth, Nielsen et al. (2002) showed that $18 \%$ surface irradiance was available at the depth limit of Danish eelgrass meadows (Secchi depth $\sim 4 \mathrm{~m}$ ), while Krause-Jensen et al. (2011) found that $28 \%$ of surface irradiance was available at the average depth limit of eelgrass in Danish coastal waters (Secchi depth between 2.5 and $8 \mathrm{~m}$ ). Combining these studies with the model results suggests that the eelgrass biomass at the depth limit represents 50-70\% of $B_{\max }$. Obviously, the biomass attenuation component is not useful for predicting depth limits (the biomass model is essentially unbounded towards deeper depths, cf. Eq. 2) and depth limits are described through disappearance of eelgrass cover, as input to the model.

\section{Seasonal variation in biomass}

The increase in eelgrass biomass from May to August followed by a decline in September and October fits well with the results from other studies at similar latitudes, which also show a biomass peak in 

al. 2014). The increase in eelgrass biomass from May to August reflects the main growth season for eelgrass with good light conditions and minimal physical exposure while the decline in biomass during autumn is a combined effect from decreasing light levels and losses of leaves and shoots during autumn storms. The timing of the biomass peak depends on latitude with earlier timing in the southern end of the distribution range and later timing towards the Arctic (Clausen et al. 2014). Hence, the model would need adjustment of the seasonal pattern if applied to eelgrass cover data from higher or lower latitudes.

The $B_{\max }$ estimate for August (Table 2) suggests a mean eelgrass biomass potential of $241 \mathrm{~g} \mathrm{DW} \mathrm{m}^{-2}$ for $100 \%$ eelgrass cover and no light limitation. This is consistent with Olesen and Sand-Jensen (1994), who investigated a broad selection of 40 temperate eelgrass meadows and found an average aboveground biomass of $245 \mathrm{~g} \mathrm{DW} \mathrm{m}^{-2}$ (10-90\% percentile range: $111-391 \mathrm{~g} \mathrm{DW} \mathrm{m}^{-2}$ ). Olesen and Sand-Jensen (1994) concluded that the maximum attainable biomass of eelgrass meadows during midsummer was relatively uniform among populations because self-shading within the stands sets an upper limit for biomass development. Probably for the same reason maximum eelgrass biomass shows no significant change with latitude (Clausen et al. 2014).

The average increase in eelgrass biomass from May to August was $129 \mathrm{~g} \mathrm{DW} \mathrm{m}^{-2}$ and represented about a doubling. Such marked seasonality from spring to summer is characteristic for eelgrass meadows (Olesen and Sand-Jensen 1994; Duarte and Chiscano1999; Clausen et al. 2014). For example, Sand-Jensen (1975) reported a quadrupling of the aboveground eelgrass biomass and a doubling of the belowground biomass from March to August in a shallow Danish embayment, paralleling a total production of about $1100 \mathrm{~g} \mathrm{DW}$ $\mathrm{m}^{-2}$ from April to October.

\section{Spatial variation and applicability of the model}

326 The estimated model translates eelgrass cover and depth into eelgrass biomass, provided that the Secchi 327 depth is also known. Analysis of the residuals suggests that the model could introduce a substantial bias (23\%-39\%, Table 3) in such biomass estimates, but this bias may also result from other factors (input data) 
introduce a bias, because these data represent light conditions in the eelgrass meadows with varying degree

331 of bias. Differences among areas in $K_{d} * z_{S D}$ for converting Secchi depths to light attenuation may also 332 introduce a bias, and it is therefore better to use Eq. (3) for the light attenuation, if $K_{d}$ is measured.

333 Variation among sites in the biomass-cover relationship was observed (Table 3). It cannot be excluded that 334 differences between observers and slight differences in methods explain part of this variation as many divers 335 contributed to the survey. If differences between observers could be ignored, site-specific variation in the 336 biomass for a given cover likely reflects differences between sites in loss factors and/or growth conditions 337 unrelated to light-attenuation in the water column (which the model accounts for). One such loss factor could 338 be grazing, e.g. by water fowl, which would affect biomass without necessarily affecting cover and therefore 339 would result in the model overestimating the actual biomass at such sites. Drifting algae, which tend to 340 accumulate in eelgrass beds (Rasmussen et al. 2013, 2015) might also reduce the aboveground biomass 341 without affecting cover and might be part of the explanation why the model overestimates the eelgrass 342 biomass at sites such as Køge Bugt and Kertinge Nor, which have been known for large occurrences of 343 drifting filamentous brown algae during the study period (Riisgård et al. 1995). By contrast, well-established 344 and dense eelgrass meadows tend to facilitate their own growth and resilience through positive feed-backs, 345 which may involve more efficient light utilization in the closed canopy, increased sedimentation and 346 improved recycling of nutrients as well as increased top-down control of epiphytic algae on leaf surfaces 347 (Gutierrez et al. 2011; Sand-Jensen et al. 2007; van der Heide et al. 2011) and may thereby maintain a larger 348 biomass at a given cover. Such positive feed-backs could explain why the model underestimated the biomass 349 at the South Funen Archipelago and The Sound, known for their well-developed eelgrass meadows (Krause350 Jensen et al. 2000).

351 The perspective is to employ the model to scale-up eelgrass cover estimates for an entire coastal ecosystem 352 to calculate nutrient and carbon budgets for eelgrass, and to compare these to similar budgets for the water 353 column and other biological components (Neckles et al. 2012). This will allow to quantitatively assess the 354 role of eelgrass in the biogeochemical cycling of elements in coastal ecosystems. 


\section{Acknowledgements}

356 We are grateful to Nikolaj Holmboe, Steen Schwaerter, Jens Sund Laursen, Mikael Hjort Jensen and Martha 357 Laursen from the local departments of the Danish Nature Agency for their help on providing data and

358 background information on eelgrass in the various coastal areas. We thank three anonymous reviewers and 359 the associate editor for their constructive comments that improved the manuscript. The study received 360 support from the Danish Nature Agency, the DEVOTES project funded under the EC $7^{\text {th }}$ framework program 361 (grant agreement no. 308392) and the COCOA project under the BONUS research program funded by the 362 EC and the Danish Research Council. 


\section{References}

Carstensen, J., D.J. Conley, J.H. Andersen and G. Ærtebjerg. 2006. Coastal eutrophication and trend reversal: A Danish case study. Limnology \& Oceanography 51: 398-408.

Carstensen, J. 2010. Censored data regression: statistical methods for analyzing Secchi transparency in shallow systems. Limnology \& Oceanography: Methods 8: 376-385.

Cebrián, J., C.M. Duarte, N. Marbà and S. Enriquez. 1997. Magnitude and fate of the production of four cooccurring western Mediterranean seagrass species. Marine Ecology Progress Series 155: 29-44.

Clausen, K.K., P. Clausen, C.C. Faelled and K.N. Mouritsen. 2012. Energetic consequences of a major change in habitat use: endangered Brent geese Branta bernicla hrota losing their main food resource. Ibis 154: $803-814$.

Clausen, K.K., D. Krause-Jensen, B. Olesen and N. Marbà. 2014. Seasonality of eelgrass biomass across gradients in temperature and latitude. Marine Ecology Progress Series 506: 71-85.

Duarte, C.M. 1991. Seagrass depth limits. Aquatic Botany 40: 363-377.

Duarte, C.M. and C.L. Chiscano. 1999. Seagrass biomass and production: a reassessment. Aquatic Botany 65: $159-174$.

Duarte, C.M., N. Marbà, D. Krause-Jensen and M. Sánchez-Camacho. 2007. Testing the predictive power of seagrass depth limit models. Estuaries and Coasts 30: 652-656.

Duarte, C.M., I.J. Losada, I.E. Hendriks, I. Mazarrasa and N. Marbà. 2013. The role of coastal plant communities for climate change mitigation and adaptation. Nature Climate Change 3: 961-968.

Fourqurean, J.W., C.M. Duarte, H. Kennedy, N. Marbà, M. Holmer, M.A. Mateo, E.T. Apostolaki, G.A. Kendrick, D. Krause-Jensen, K.J. McGlathery and O. Serrano. 2012. Seagrass ecosystems as a globally significant carbon stock. Nature Geoscience 5: 505-509.

Gallegos, C.L., P.J. Werdell, and C.R. McClain. 2011. Long-term changes in light scattering in Chesapeake Bay inferred from Secchi depth, light attenuation, and remote sensing measurements. Journal of Geophysical Research 116: C00H08. doi:10.1029/2011JC007160. 
Gutiérrez, J.L., C.G. Jones, J.E. Byers, K.K. Arkema, K. Berkenbusch, J.A. Commito, C.M. Duarte, S.D. Hacker, J.G. Lambrinos, I.E. Hendriks, P.J. Hogarth, M.G. Palomo and C. Wild. 2011. Physical ecosystem engineers and the functioning of estuaries and coasts. Treatise on Estuarine and Coastal Science 7: 53-81.

Hemminga, M.A. and C.M. Duarte. 2000. Seagrass ecology. Cambridge University Press, Cambridge.

Koch, E.M. 2001. Beyond light: physical, geological, and geochemical parameters as possible submersed aquatic vegetation habitat requirements. Estuaries 24: 1-17.

Koenings, J.P. and J.A. Edmundson. 1991. Secchi disk and photometer estimates of light regimes in Alaskan lakes_-effects of yellow color and turbidity. Limnology \& Oceanography 36: 91-105.

Krause-Jensen, D., A.L. Middelboe, K. Sand-Jensen and P.B. Christensen. 2000. Eelgrass, Zostera marina, growth along depth gradients: Upper boundaries of the variation as a powerful predictive tool. Oikos 91: 233-244.

Krause-Jensen, D., M.F. Pedersen and C. Jensen. 2003. Regulation of eelgrass (Zostera marina) cover along depth gradients in Danish coastal waters. Estuaries 26: 866-877.

Krause-Jensen, D., J. Carstensen, S.L. Nielsen, T. Dalsgaard, P.B. Christensen, H. Fossing and M.B. Rasmussen. 2011. Sea bottom characteristics affect depth limits of eelgrass Zostera marina. Marine Ecology Progress Series 425: 91-102.

Marbá, N, D. Krause-Jensen, T. Alcoverro, S. Birk, A. Pedersen, J.M. Neto, S. Orfanidis, J.M. Garmendia, I. Muxika, A. Borja, K. Dencheva and C.M. Duarte. 2013. Diversity of European seagrass indicators Patterns within and across regions. Hydrobiologia 704: 265-278. DOI 10.1007/s10750-012-1403-7.

McGlathery, K.J., L.K. Reynolds, L.W. Cole, R.J. Orth, S.R. Marion and A. Schwarzschild. 2012. Recovery trajectories during state change from bare sediment to eelgrass dominance. Marine Ecology Progress Series 448: 209-221.

Neckles, H.A., B.S. Kopp, B.J. Peterson and P.S. Pooler. 2012. Integrating scales of seagrass monitoring to meet conservation needs. Estuaries and Coasts 35: 23-46. DOI 10.1007/s12237-011-9410-x. 
Nielsen, S.L., K. Sand-Jensen, J. Borum and O. Geertz-Hansen. 2002. Depth colonization of eelgrass (Zostera marina) and macroalgaeas determined by water transparency in Danish coastal waters. Estuaries 25: $1025-1032$.

Olesen, B. 1996. Regulation of light attenuation and eelgrass Zostera marina depth distribution in a Danish embayment. Marine Ecology Progress Series 134: 187-194.

Olesen, B. and K. Sand-Jensen. 1994. Biomass-density patterns in the temperate seagrass Zostera marina. Marine Ecology Progress Series 109: 283-291.

Pedersen, M.F. and J. Borum. 1993. An annual nitrogen budget for a seagrass Zostera marina population. Marine Ecology Progress Series 101: 169-169.

Pedersen, T.M., K. Sand-Jensen, S. Markager and S.L. Nielsen. 2014. Optical changes in a eutrophic estuary during reduced nutrient loadings. Estuaries and Coasts 37: 880-892. DOI 10.1007/s12237-013-9732-y

Platt, T., A.D. Jassby. 1976. The relationship between photosynthesis and light for natural assemblages of coastal marine phytoplankton. Journal of Phycology 12: 421-430.

Plummer, M.L., C.J. Harvey, L.E. Anderson, A.D. Guerry and M.H. Ruckelshaus. 2013. The role of eelgrass in marine community interactions and ecosystem services: Results from ecosystem-scale food web models. Ecosystems 16: 237-251. DOI: 10.1007/s10021-012-9609-0.

Rasmussen, J.R., M.F. Pedersen, B. Olesen, S.L. Nielsen and T.M. Pedersen. 2013. Temporal and spatial dynamics of ephemeral drift-algae in eelgrass, Zostera marina, beds. Estuarine Coastal Shelf Science 119: $167-175$.

Rasmussen, J.R., K. Dromph, C. Göke and D. Krause-Jensen. 2015. Reduced cover of drifting macroalgae following nutrient reduction in Danish coastal waters. Estuaries and Coasts. DOI 10.1007/s12237-0149904-4.

Riisgård, H.U., P.B. Christensen, N.J. Olesen, J.K. Petersen, M.M. Møller and P. Andersen. 1995. Biological structure in a shallow cove (Kertinge Nor, Denmark) - control by benthic nutrient fluxes and suspensionfeeding ascidians and jellyfish. Ophelia 41: 329-344.

Sand-Jensen K. 1975. Biomass, net production and growth dynamics in an eelgrass (Zostera marina L.) population in Vellerup Vig. Denmark. Ophelia 14: 185-201. 
442 Sand-Jensen, K., J. Borum. 1991. Interactions among phytoplankton, periphyton, and macrophytes in 443 temperate freshwaters and estuaries. Aquatic Botany 41, 137-175.

444 Sand-Jensen, K., T. Binzer and A.L. Middelboe. 2007. Scaling of photosynthetic production of aquatic 445 macrophytes - a review. Oikos 116: 280-294, doi: 10.1111/j.2006.0030-1299.15093.x.

446 van der Heide, T., E.H. van Nes, M.M. van Katwijk, H. Olff and A.J.P. Smolders. 2011. Positive feedbacks 447 in seagrass ecosystems - Evidence from large-scale empirical data. PLoS ONE 6(1): e16504.

448 doi:10.1371/journal.pone.0016504.

449 
Table 1 Overview of data sets used for estimating the eelgrass aboveground biomass-cover relationship. For each coastal site is listed the number of observations, distributed over number of years, number of transects and the specific months sampled (by month number, i.e. 3=March, 4=April, etc.). Means and ranges for the variables used in the relationship are shown. Annual means (March-September) of Secchi depth were used and no range is given for sites with a single sampling year.

\begin{tabular}{|c|c|c|c|c|c|c|c|c|c|c|c|c|}
\hline \multirow[t]{2}{*}{ Coastal site } & \multirow{2}{*}{$\begin{array}{l}\# \text { of } \\
\text { years }\end{array}$} & \multirow{2}{*}{$\begin{array}{l}\text { Months } \\
\text { sampled }\end{array}$} & \multirow{3}{*}{$\begin{array}{c}\text { \# of } \\
\text { transect } \\
\text { s }\end{array}$} & \multirow{3}{*}{$\begin{array}{l}\# \text { of } \\
\text { obs. }\end{array}$} & \multicolumn{2}{|c|}{ Secchi depth (m) } & \multicolumn{2}{|c|}{ Transect depth (m) } & \multicolumn{2}{|c|}{ Cover (\%) } & \multicolumn{2}{|c|}{ Biomass $\left(\mathrm{g} \mathrm{DW} \mathrm{m}^{-2}\right)$} \\
\hline & & & & & Mean & Range & Mean & Range & Mean & Range & Mean & Range \\
\hline & & & & & & & & & & & & \\
\hline Flensborg Fjord & 7 & $3-6,8-9$ & 1 & 83 & 5.0 & $4.4-5.4$ & 2.8 & $1.0-5.0$ & 66 & $1-100$ & 148 & $2.8-546$ \\
\hline Helnæs Bugt & 1 & 9 & 7 & 38 & 5.6 & & 1.5 & $0.7-2.5$ & 72 & $50-95$ & 176 & $64-312$ \\
\hline Kertinge Nor & 1 & 9 & 4 & 12 & 2.2 & & 2.0 & $0.7-2.5$ & 100 & 100 & 122 & $31-240$ \\
\hline Køge Bugt & 6 & $4-10$ & 4 & 156 & 7.1 & $6.6-7.5$ & 4.3 & $0.7-7.8$ & 45 & $1-100$ & 113 & $0.2-573$ \\
\hline Odense Fjord & 3 & $5-6,8-10$ & 3 & 120 & 3.2 & $2.8-3.5$ & 1.6 & $0.8-3.2$ & 81 & $20-100$ & 128 & $5.0-388$ \\
\hline Roskilde Fjord & 6 & $3-8$ & 10 & 105 & 3.9 & $2.7-4.5$ & 2.4 & $1.0-6.0$ & 46 & $2-100$ & 113 & 2.9-399 \\
\hline South Funen & 1 & 9 & 2 & 24 & 6.5 & & 3.7 & $2.6-5.2$ & 93 & $75-100$ & 91 & $34-178$ \\
\hline \multicolumn{13}{|l|}{ Archipelago } \\
\hline The Sound & 10 & $5-9$ & 11 & 253 & 7.8 & 7.4-8.7 & 3.3 & $1.0-6.3$ & 86 & $10-100$ & 155 & $3.9-511$ \\
\hline
\end{tabular}


Table 2 Parameter estimates obtained from Eq. (6) using 791 eelgrass biomass observations (logtransformed). $\mathrm{SE}=$ standard error of the parameter estimate.

\begin{tabular}{|c|c|c|c|c|}
\hline Parameter & Estimate & SE & $t$-test & Probabili \\
\hline $\boldsymbol{k}_{c}$ & 54.26 & 7.82 & 6.94 & $<.0001$ \\
\hline$I_{0} / I_{\text {sat }}$ & 3.12 & 0.38 & 8.28 & $<.0001$ \\
\hline $\log \left(B_{\max }\right)($ Mar $)$ & 4.79 & 0.15 & 32.04 & $<.0001$ \\
\hline $\log \left(B_{\max }\right)(\mathrm{Apr})$ & 4.93 & 0.16 & 30.33 & $<.0001$ \\
\hline $\log \left(B_{\max }\right)($ May) & 4.72 & 0.13 & 35.06 & $<.0001$ \\
\hline $\log \left(B_{\max }\right)(\mathrm{Jun})$ & 5.16 & 0.12 & 44.50 & $<.0001$ \\
\hline $\log \left(B_{\max }\right)(\mathrm{Jul})$ & 5.13 & 0.12 & 44.01 & $<.0001$ \\
\hline $\log \left(B_{\max }\right)(\mathrm{Aug})$ & 5.48 & 0.08 & 65.91 & $<.0001$ \\
\hline $\log \left(B_{\max }\right)($ Sep $)$ & 5.12 & 0.10 & 52.79 & $<.0001$ \\
\hline $\log \left(B_{\max }\right)$ (Oct) & 5.20 & 0.12 & 42.67 & $<.0001$ \\
\hline
\end{tabular}


Table 3 Residual variation from estimating Eq. (6) among coastal sites. For each coastal site is listed the mean of the residuals, the standard error of the mean (SE), the $t$-statistic for testing if the mean equals zero and its associated probability.

\begin{tabular}{lcccc}
\hline Coastal site & Mean & SE & $t$ & $p$ \\
\hline Flensborg Fjord & 0.256 & 0.067 & 3.82 & 0.0001 \\
Helnæs Bugt & 0.332 & 0.098 & 3.38 & 0.0007 \\
Kertinge Nor & 0.190 & 0.174 & 1.09 & 0.2770 \\
Køge Bugt & 0.298 & 0.048 & 6.16 & $<0.0001$ \\
Odense Fjord & -0.117 & 0.055 & -2.13 & 0.0335 \\
Roskilde Fjord & -0.016 & 0.059 & -0.28 & 0.7823 \\
South Funen Archipelago & -0.258 & 0.123 & -2.10 & 0.0363 \\
The Sound & -0.237 & 0.038 & -6.25 & $<0.0001$ \\
\hline
\end{tabular}




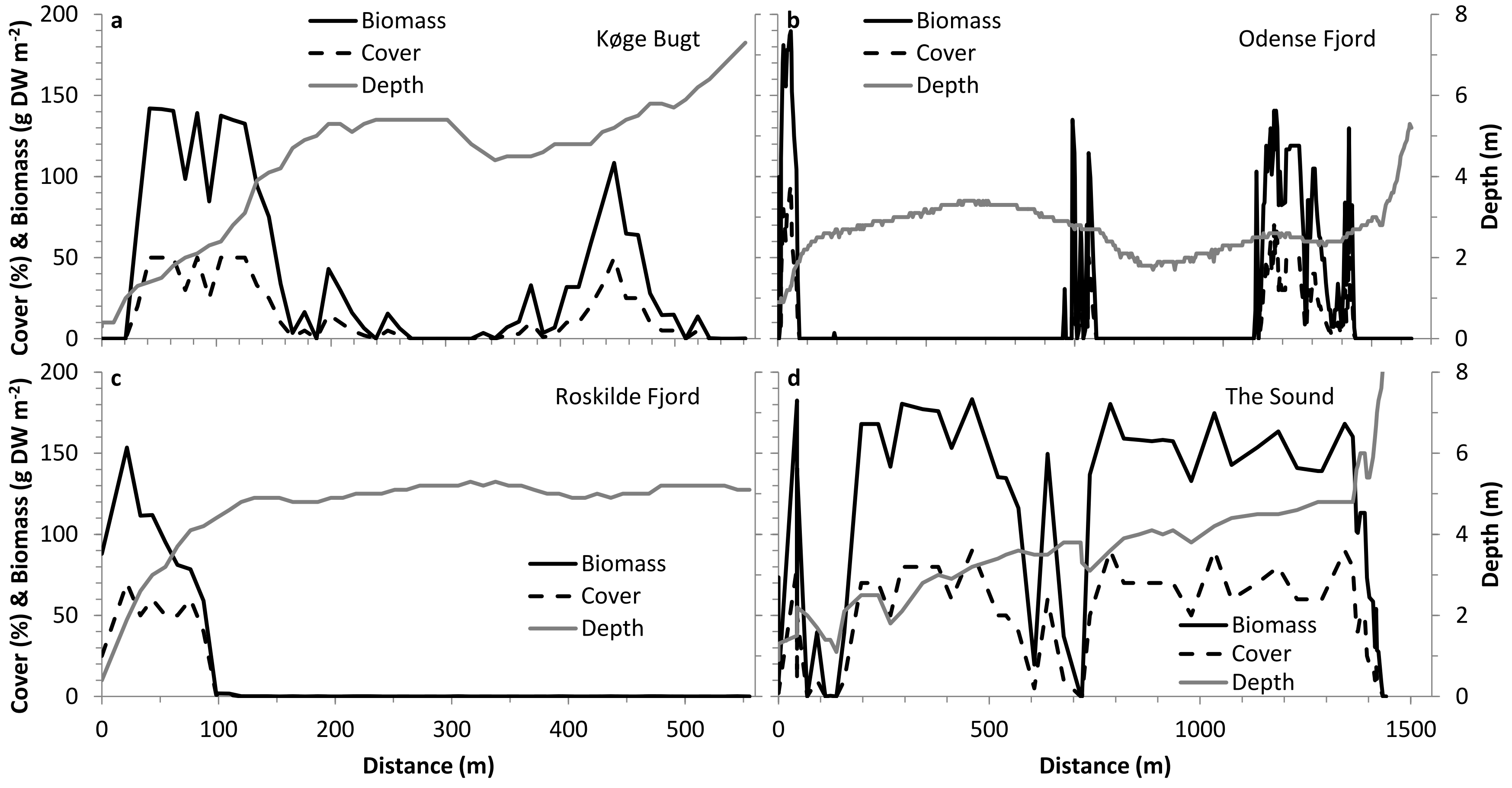




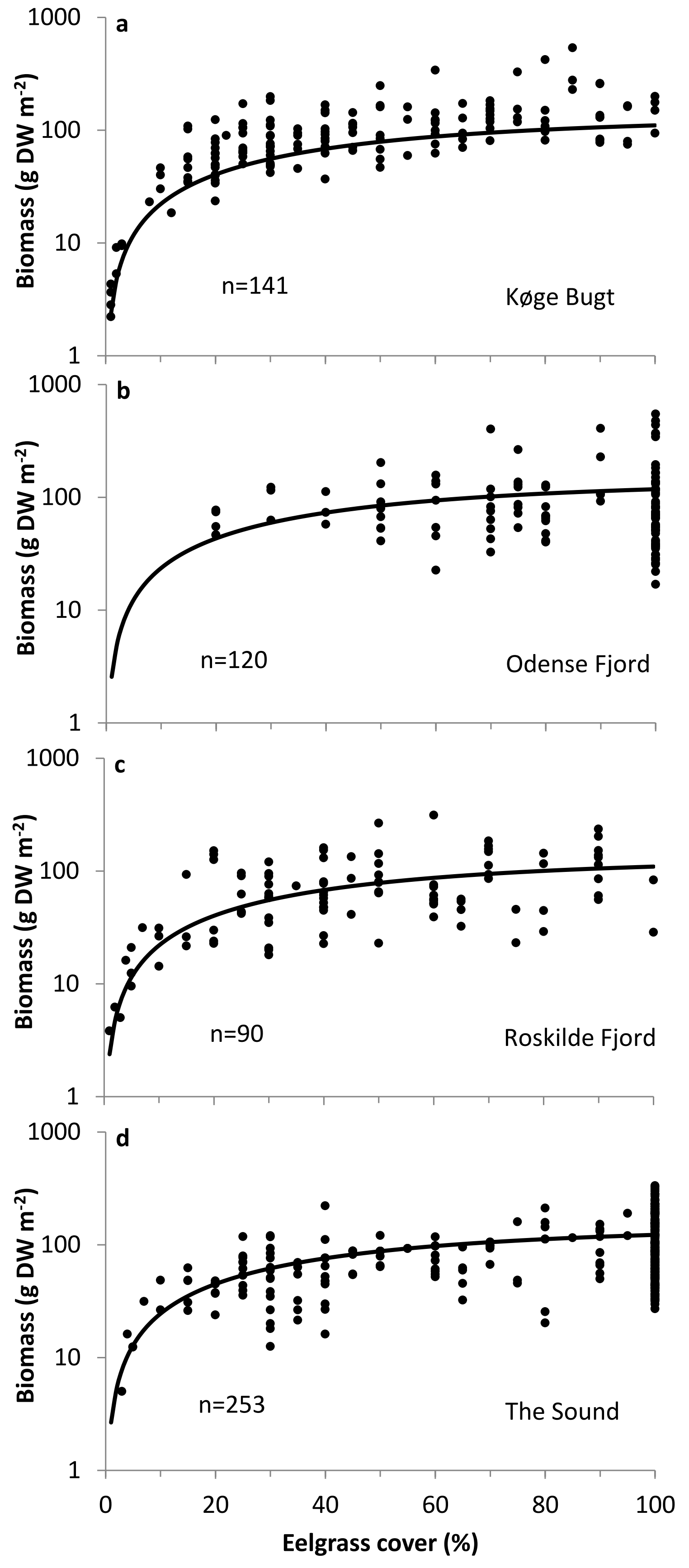



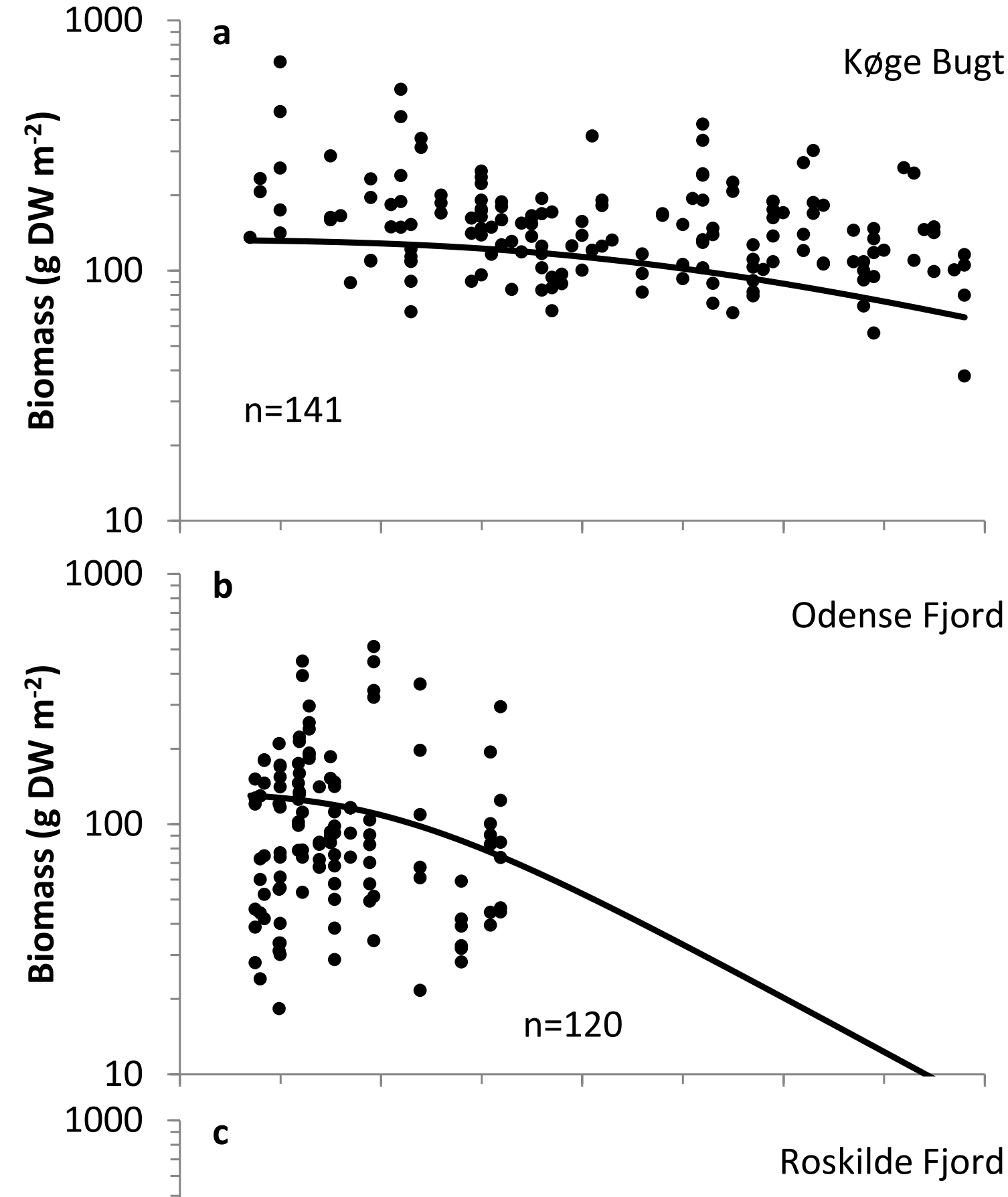

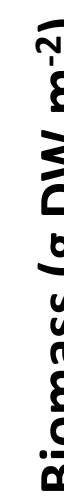
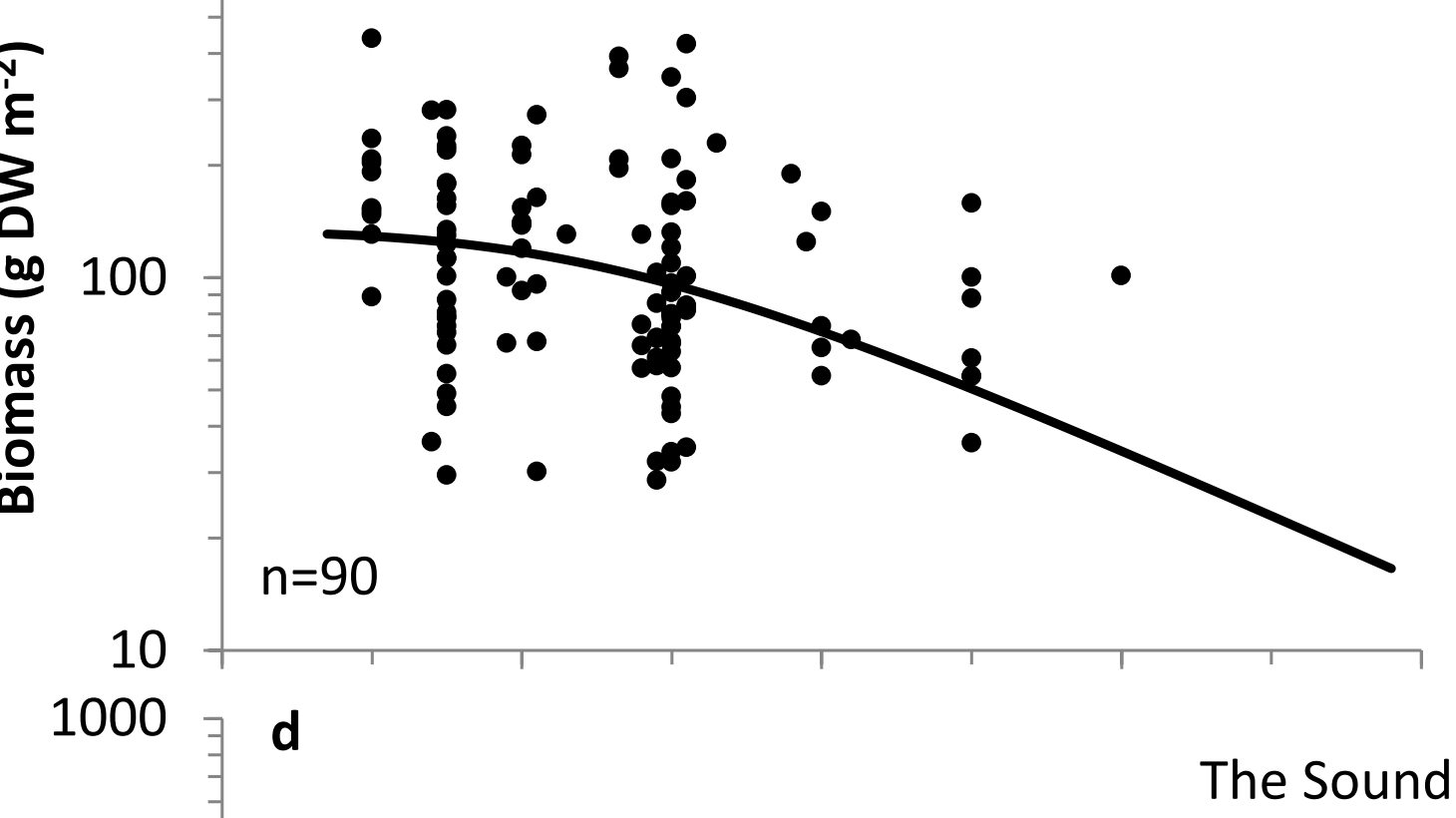

s's

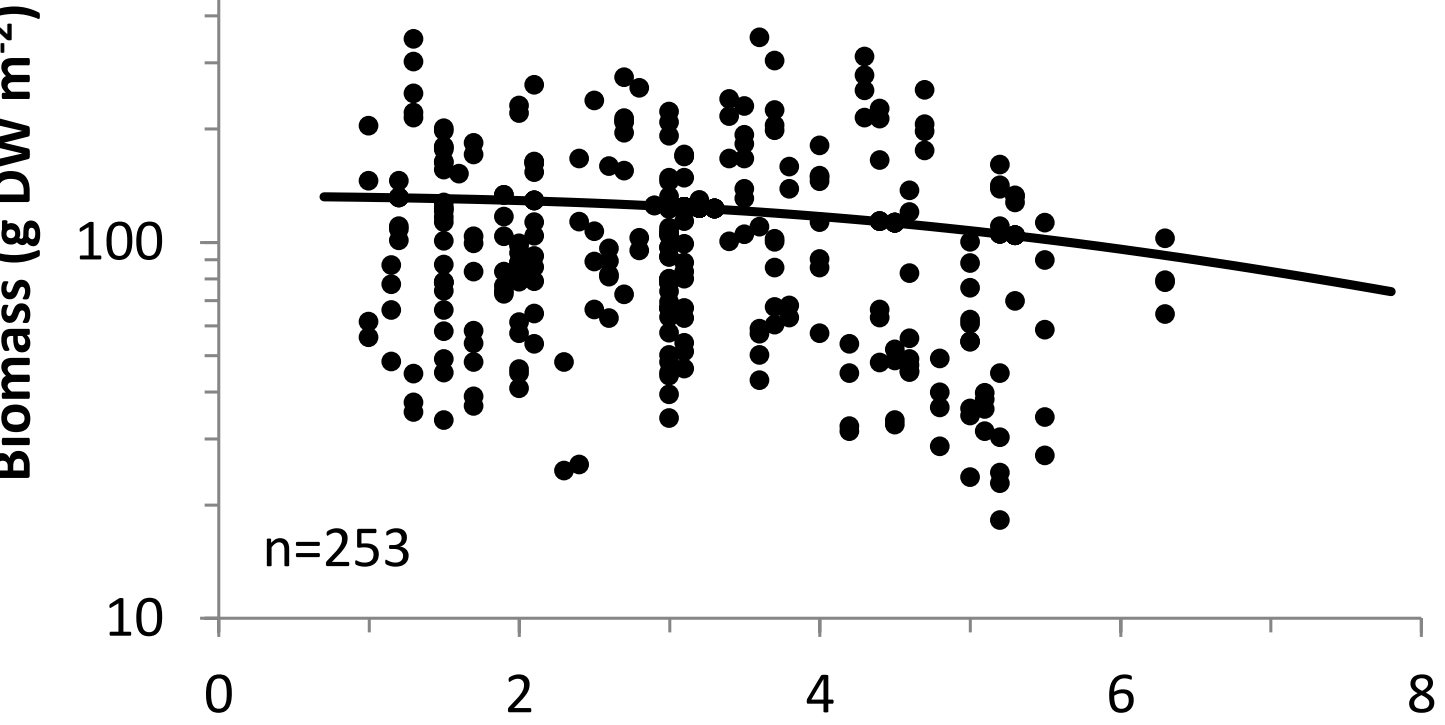

Depth (m) 


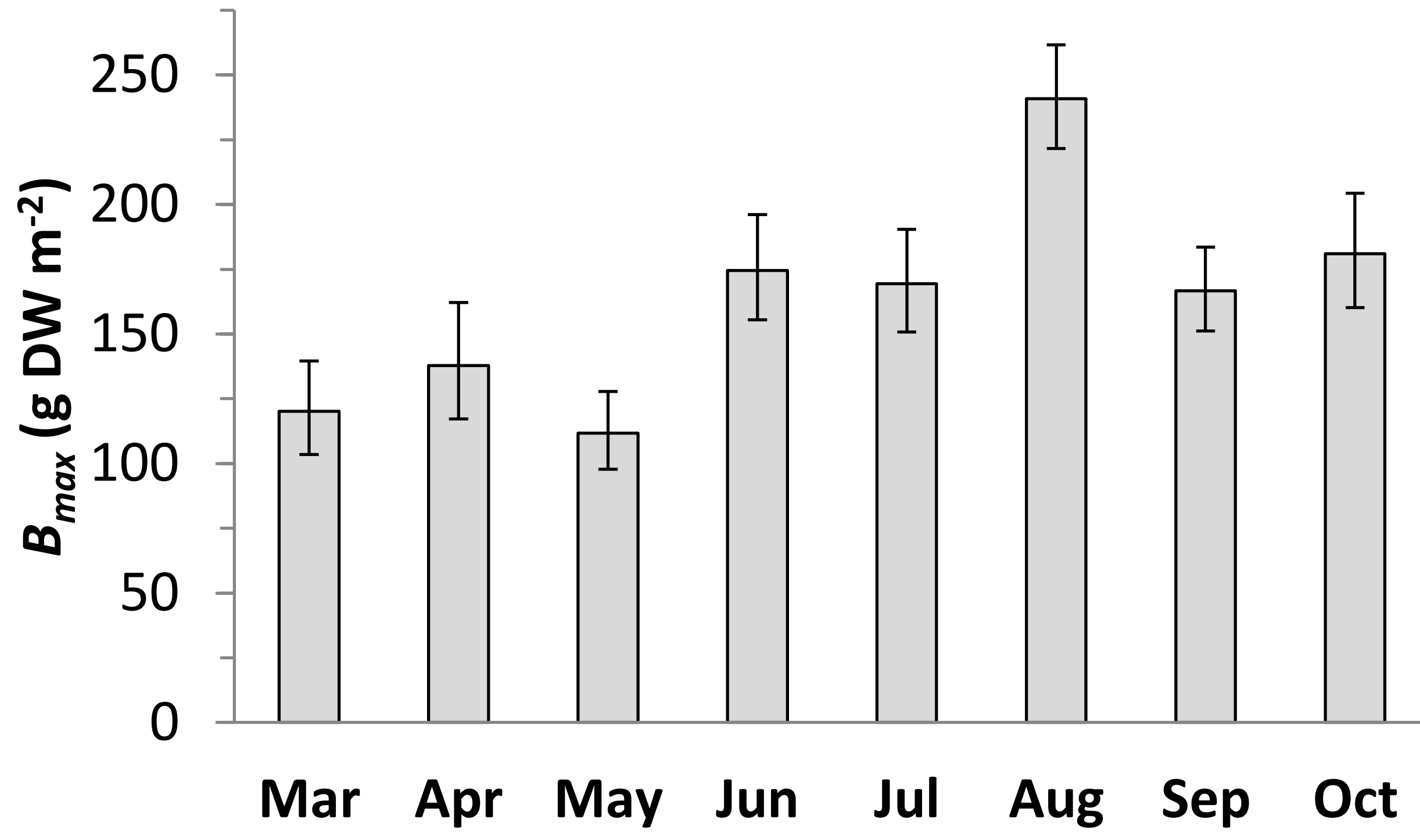




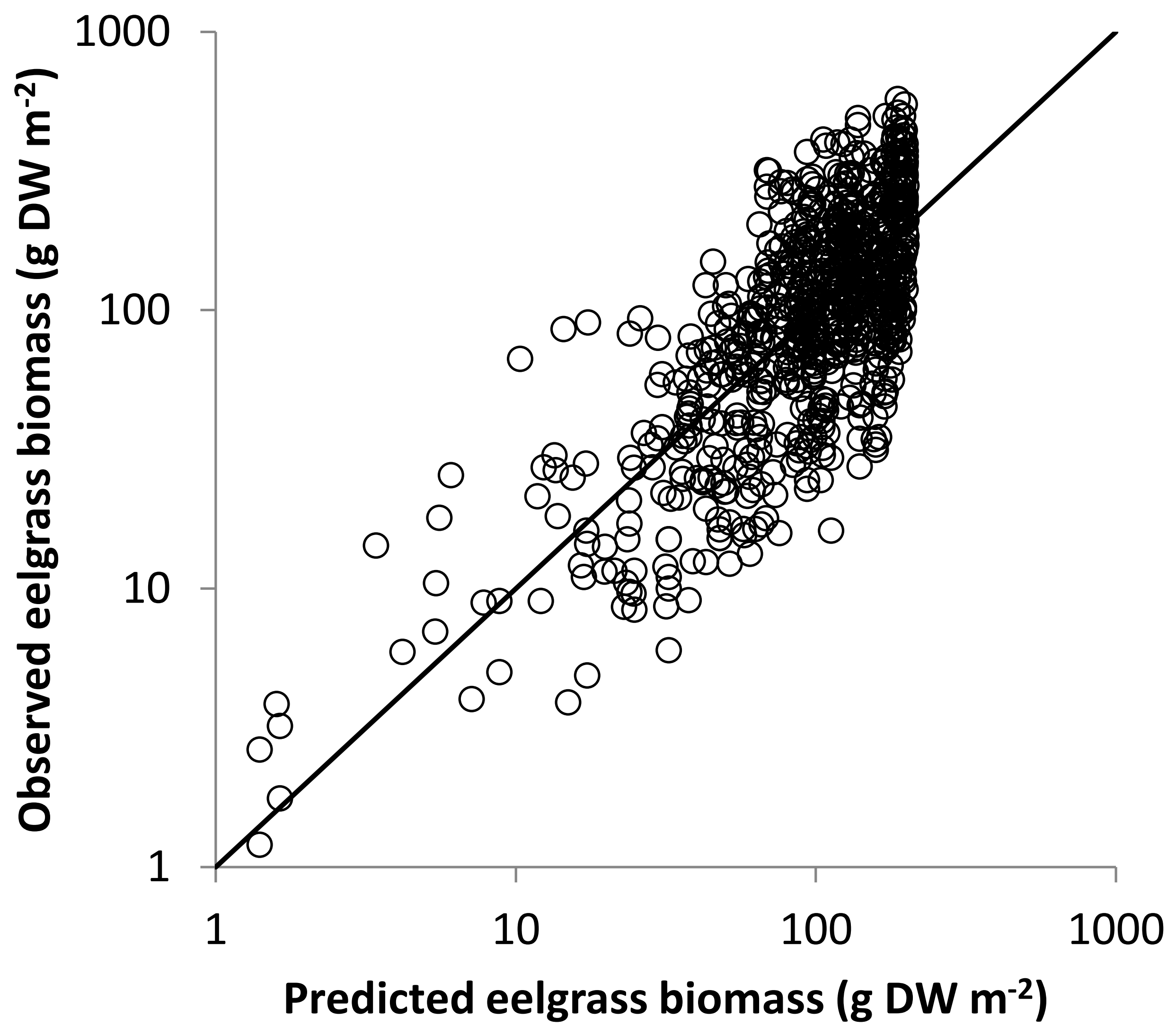




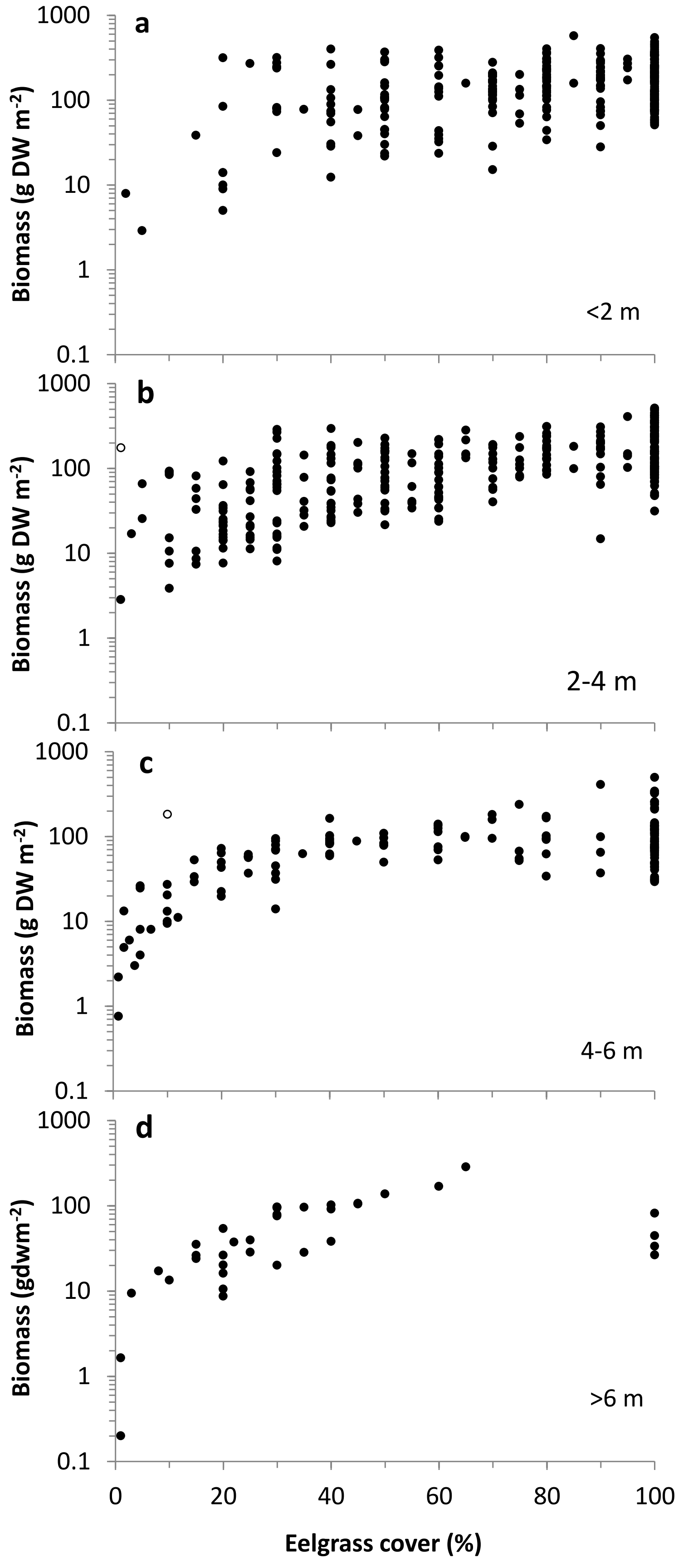




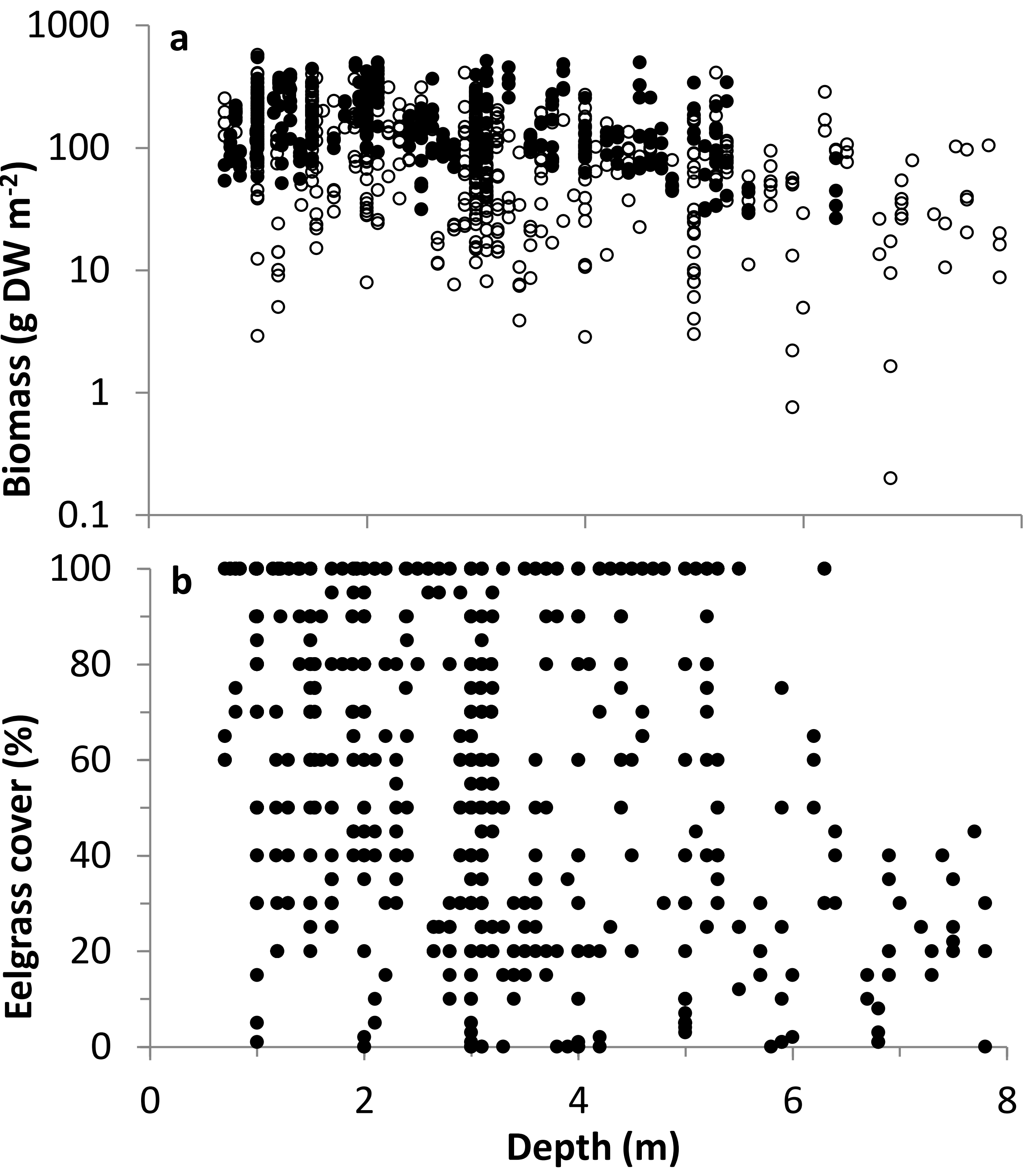




\section{FIGURE LEGENDS}

Fig. 1 Eelgrass aboveground biomass (a) and eelgrass cover (b) versus depth shown for all 791 samples. a) closed symbols are observations with $100 \%$ cover and open symbols have less than $100 \%$ eelgrass cover

Fig. 2 Eelgrass aboveground biomass versus cover shown for different depth. a: 0.5-2 m, b: 2-4 m, c: 4-6 m, d: 6-8 $\mathrm{m}$. Two outliers are shown with open symbols

Fig. 3 Predicted versus observed eelgrass aboveground biomass.

Fig. 4 Monthly estimates of maximum aboveground eelgrass biomass at $100 \%$ cover $\left(B_{\max }\right)$. Estimates were obtained from back-transforming the estimates in Table 2. Error bars show the standard errors of the monthly estimates

Fig. 5 Marginal relationships between aboveground eelgrass biomass and depth for four selected sites. Variations in eelgrass cover, interannual variations in Secchi depth and month of sampling were accounted for by adjusting observations (dots) and the modeled relationships (solid line) to a common eelgrass cover of $100 \%$ and an average over all months from March to October using the estimated relationship (Eq. 6) and annual means of Secchi depth. The four selected sites had the most biomass observations and a broad span in Secchi depths and eelgrass depth ranges (Table 1)

Fig. 6 Marginal relationships between aboveground eelgrass biomass and cover for four selected sites. Variations in sampling depth, interannual variations in Secchi depth and month were accounted for by adjusting observations (dots) and the modeled relationships (solid line) to a mean sampling depth (Table 1) and an average over all months from March to October using the estimated relationship (Eq. 6) and annual means of Secchi depth. The four selected sites had the most biomass observations and a broad span in Secchi depths and eelgrass depth ranges (Table 1)

Fig. 7 Application of the estimated eelgrass biomass vs. cover relationship to four transects from selected sites monitored in 2013. Depth and eelgrass cover are measured along transects of variable length and 
converted to eelgrass biomass using Eq. (6). Secchi depths used in the equations were $7.2 \mathrm{~m}$ (Køge Bugt), $4.1 \mathrm{~m}$ (Odense Fjord), $3.7 \mathrm{~m}$ (Roskilde Fjord), and $8.9 \mathrm{~m}$ (The Sound) 


\section{Supplementary information}

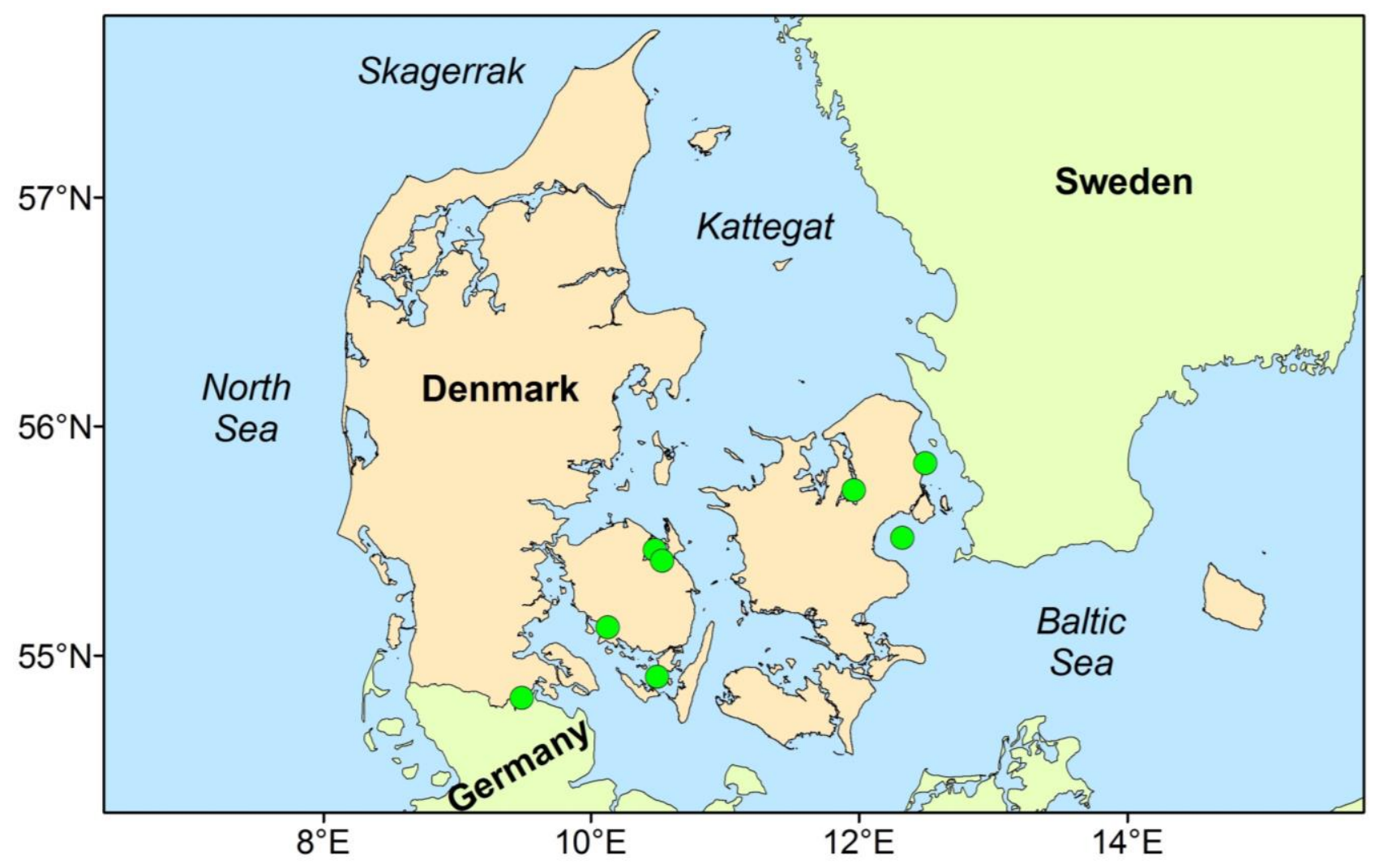

Fig. S1: Location of coastal sites where eelgrass biomass was sampled. 